\title{
Materiais pedagógicos na perspectiva da Educação Matemática Crítica
}

\author{
Pedagogical Math Material in a Critical Education approach
}

\author{
Simone Regina dos Reis ${ }^{1}$ e Carmen Vieira Mathias ${ }^{2}$ \\ ${ }^{1}$ PROFMAT - Centro Universitário Franciscano, UNIFRA, Brasil \\ simone_reis@msn.com \\ ${ }^{2}$ Universidade Federal de Santa Maria - RS, Brasil \\ carmenmathias@gmail.com
}

\begin{abstract}
Resumo
Pesquisas em educação matemática crítica (EMC) têm apontado à necessidade urgente de produção de materiais didáticos que enfatizem situações reais vivenciadas pelos alunos para que a aprendizagem se torne mais significativa. Tendo em vista contribuir com as pesquisas em EMC, neste artigo são apresentadas sugestões para o ensino da Matemática Financeira (MF) por meio de uma proposta pedagógica orientada pela EMC. É fundamental que, ao aplicar a presente proposta, o professor objetive conscientizar os alunos para a importância dos conceitos de MF como instrumento e para compreender a realidade em que se inserem. Os conteúdos propostos, nas atividades pedagógicas, contemplam o estudo sobre conceitos de taxas, aplicações e empréstimos, para que os alunos aprendam como a MF é utilizada socialmente. Ainda, sugere-se a resolução dos exemplos propostos, por meio de planilhas eletrônicas, por estas oferecerem mais recursos do que uma calculadora.
\end{abstract}

Palavras-chave: Educação crítica. Matemática financeira. Planilha eletrônica

\begin{abstract}
Critical research in mathematics education (CME) has pointed out the urgent need to produce educational materials that emphasize real situations experienced by students so that learning becomes more meaningful. To contribute to the research on CME, in this article is presented teaching suggestions to Financial Mathematics (FM) through a pedagogical proposal guided by CME. It is essential that, when applying this proposal, the teacher aims to raise students' awareness of the importance of the concepts of FM as a tool and to understand the reality in which they operate. The proposed content by pedagogic activities includes the study of concepts of exchange, investments and loans, for students to learn how FM is used socially. Still, this study suggests solving the proposed examples, through spreadsheets, because it offers more features than a calculator.
\end{abstract}

Keywords: Critical education. Financial mathematics. Spreadsheet 


\section{Introdução}

A Matemática sempre desempenhou um papel único no desenvolvimento das sociedades. Compõe-se de ideias, métodos e procedimentos que são utilizados para analisar e resolver situações-problema, bem como para raciocinar, representar e comunicar. Nos seus diferentes modos de pensar configura procurar regularidades, fazer e testar conjecturas, localizar-se no tempo e no espaço, raciocinar logicamente, buscar razoabilidade de resultados, abstrair, generalizar e demonstrar.

As diferentes e múltiplas Matemáticas, suas linguagens, procedimentos e formas específicas de pensar, devem organizar situações de aprendizagem nas quais os conteúdos sejam tratados de forma que relacionem o conhecimento científico aos problemas que fazem parte da vida do aluno para que o mesmo faça sentido.

Tendo por base a Lei de Diretrizes e Bases (LDB), os Parâmetros Curriculares Nacionais (PCN) são diretrizes propostas pelo Governo Federal, como base referencial para que escolas municipais e estaduais construam seus currículos. Além de propor os conteúdos a serem transmitidos, nas mais diferentes áreas do conhecimento, os PCN oferecem práticas de organização dos conhecimentos, modos de abordagem dos conteúdos e exemplos de comportamentos a serem seguidos pelos professores nas mais diferentes circunstâncias. Desse modo, Lima e Zanlorense (2009, p.14) afirmam que basta adequá-lo às peculiaridades de cada região, com propostas atuais, inovadoras, para uma sociedade democrática, no exercício da cidadania.

Independentemente da condição socioeconômica e da localização da escola, a intenção dos PCN é fornecer aos estudantes brasileiros meios para progredir no trabalho e ter acesso igualitário ao conhecimento. Além disso, tais diretrizes visavam à autonomia da escola, a participação da comunidade na gestão escolar e descentralização das ações.

O novo Ensino Médio, em termos da lei, assume a responsabilidade de completar a educação básica. Seja este preparatório para o ensino superior ou profissionalizante, significa preparar para a vida, qualificar para a cidadania e capacitar para a aprendizagem permanente, em eventual prosseguimento dos estudos ou diretamente para o mundo do trabalho.

E uma formação com tal ambição exige métodos de aprendizagem compatíveis, ou seja, é preciso prover condições efetivas para que os alunos possam comunicar-se e argumentar, defrontar-se com problemas, compreendê-los e resolvê-los, participar de um convívio social que lhes oportunize se realizarem como cidadãos, fazer escolhas e proposições, tomar gosto pelo conhecimento, bem como aprender a aprender.

Ao ingressar na docência em escola pública, um professor realmente comprometido deve sentir a necessidade de ensinar uma Matemática que modifique a realidade dos alunos. Uma Matemática não somente modificada por tendências pedagógicas, 
mas com um embasamento teórico suficiente, necessário e fundamental.

Essas tendências, às vezes, tem confundido professores a não abordarem os conteúdos matemáticos com a formalidade necessária. Além disso, acabam criando situações pedagógicas irreais, que não geram conhecimento a estes alunos.

A realidade em nossas escolas é de crianças com grande dificuldade na disciplina e sem incentivo para estudála. Com o currículo pré-determinado por um órgão maior, acaba que nos currículos são apresentados conteúdos não condizentes com a realidade vivenciada pelos alunos. Os livros didáticos apresentados na escola são oriundos de centros maiores e, portanto desenvolvem conteúdos que devem ser trabalhados tendo em vista a necessidade da região a qual estão inseridos.

Desta forma, sente-se a necessidade de criar um material pedagógico que sirva de sugestão aos educadores, com a finalidade de fornecer atividades pedagógicas contextualizadas para que os alunos saibam identificar, interpretar, avaliar e criticar a matemática, a partir de situações reais vivenciadas.

Neste artigo, apresentaremos uma proposta de material pedagógico de Matemática Financeira (MF), na perspectiva de uma Educação Matemática Crítica, que foi objeto de estudo na dissertação "Matemática Financeira na perspectiva da Educação Matemática Crítica."

\section{Matemática Financeira e a Educação Matemática Crítica}

Para o ensino de Matemática Financeira (MF), os PCN abordam conteúdos dentro do Tema 1- Álgebra: números e funções, destacando como relacioná-los com atividades no mundo real, destacando que a Álgebra, na vivência cotidiana se apresenta com enorme importância enquanto linguagem, como na variedade de gráficos presentes diariamente nos noticiários e jornais, e também enquanto instrumento de cálculos de natureza financeira e prática, em geral. (BRASIL, 2000, p.120).

Ainda os PCN sugerem uma aplicação para o ensino de funções, que, ao deter-se no estudo de casos especiais, não deve descuidar de mostrar que o que está sendo aprendido permite um olhar mais crítico e analítico sobre as situações descritas. As funções exponenciais e logarítmicas, por exemplo, são usadas para descrever a variação de duas grandezas em que o crescimento da variável independente é muito rápido, sendo aplicada em áreas do conhecimento como matemática financeira, crescimento de populações, intensidade sonora, $\mathrm{pH}$ de substâncias e outras. (BRASIL, 2000, p.121).

Em uma versão mais recente dos PCN, destaca-se que o trabalho com Números e Operações, deve, proporcionar aos alunos uma diversidade de situações, de forma a capacitá-los a resolver problemas do quotidiano, tais como: operar com frações, em especial com porcentagens. Por exemplo, o trabalho com esse bloco de conteúdos deve tornar o aluno, ao 
final do ensino médio, capaz de decidir sobre as vantagens/desvantagens de uma compra à vista ou a prazo; avaliar o custo de um produto em função da quantidade; conferir se estão corretas informações em embalagens de produtos quanto ao volume; calcular impostos e contribuições previdenciárias; avaliar modalidades de juros bancários. (BRASIL, 2006, p.71).

Segundo Borba (2001), surge na década de 80, na Educação Matemática (EM) o movimento da Educação Matemática Crítica (EMC), que se preocupa fundamentalmente com os aspectos políticos da educação matemática, ou ainda, com questões ligadas ao tema poder.

Para Skovsmose (2001) para que a educação, tanto como prática quanto como pesquisa, seja crítica, ela deve, discutir condições básicas para a obtenção do conhecimento, deve estar a par dos problemas sociais, das desigualdades, da supressão etc., e deve tentar fazer da educação uma força social progressivamente ativa. (SKOVSMOSE, 2001, p. 101).

Nessa perspectiva, o autor ainda resume algumas ideias essenciais da Educação Crítica (EC) em poucas afirmações. Inicialmente destaca a importância da relação entre professor e alunos, de modo que o processo educacional deve ser entendido como um diálogo.

O autor destaca também três pontos-chave da EC, a saber:

- O envolvimento dos estudantes no controle do processo educacional, pois os estudantes carregam uma experiência geral, que no diálogo com o professor, permite identificar assuntos relevantes para o processo educacional, visto que para desenvolver uma competência crítica, a qual não pode ser imposta aos estudantes, e sim desenvolvida com base na capacidade já existente;

- A consideração crítica de conteúdos pelo fato do processo educacional envolver pessoas, deve também envolver um assunto, o currículo crítico. Por conseguinte, apresenta questões relacionadas a um currículo crítico: aplicabilidade, interesse, pressupostos, função e limitações;

- O direcionamento do processo de ensino-aprendizagem para a resolução de problemas, isto é, o problema deve ser concebido como relevante na perspectiva dos estudantes, ou seja, algo próximo das experiências destes e que tenha uma relação próxima com problemas sociais objetivamente existentes.

Desse modo, o que significa ensinar MF na perspectiva de uma EMC? Significa explorar uma MF que desenvolva competências, que torne os estudantes participativos e críticos no modo como a MF realiza-se em suas vidas. Isso implicaria em não apenas saber usar técnicas matemáticas ou desenvolver capacidade de cálculo, mas também desenvolver competências associadas à reflexão.

Conforme Paiva e Sá (2011), a MF deve buscar "desenvolver um projeto de educação comprometido com o desenvolvimento de capacidades que permitam intervir na realidade para transformá-la". Isso sugere desenvolver conceitos de MF que forneçam aos estudantes condições de analisar uma 
situação crítica, bem como buscar alternativas para resolvê-la. Compete também ao professor apresentar informações que refletem questões significativas na sociedade, situações significativas para o aluno.

\section{Uma proposta de ensino de MF}

A proposta didática que apresentaremos neste trabalho se diferencia dos demais, pois objetiva relacionar conhecimento científico a problemas reais da vida do aluno para que os mesmos se tornem significativos e gerem aprendizagens. Conforme os PCN, no Ensino Médio, etapa final da escolaridade básica, a Matemática deve ser compreendida como uma parcela do conhecimento humano essencial para a formação de todos os jovens, que contribui para a construção de uma visão de mundo, para ler e interpretar a realidade e para desenvolver capacidades que deles serão exigidas ao longo da vida social e profissional. (BRASIL, 2000, p.111).

Desta forma, justifica-se a abordagem de conteúdos de MF a partir de reportagens, de situações vividas pelos alunos ou de informações que lhes serão úteis em algum momento de sua vida social e profissional. Assim, aprender Matemática de uma forma contextualizada, integrada e relacionada a outros conhecimentos traz em si o desenvolvimento de competências e habilidades que são formadoras, à medida que instrumentalizam e estruturam o pensamento do aluno, capacitando-o para compreender e interpretar situações para se apropriar de linguagens específicas, argumentar, analisar e avaliar, tirar conclusões próprias, tomar decisões, generalizar e para muitas outras ações necessárias à sua formação. (BRASIL, 2000, p.111).

É fundamental que, ao aplicar a presente proposta, o professor objetive conscientizar os alunos sobre a importância dos conceitos de MF como instrumentos e formas de compreender e dominar a realidade. Conforme Alves, Fialho e Matos (2003) utilizar uma metodologia que vise uma EMC importa em envolver os alunos, analisar e descrever suas práticas, explicitar os recursos que movimentam e criar situações e práticas que se mobilizem.

Desta forma, com a propósito de estudar conceitos de juros, taxas, aplicações e empréstimos pretende-se, a partir de uma EMC, contribuir para que os alunos aprendam como a MF é utilizada socialmente, e ainda, conforme Alves, Fialho e Matos (2003), "para formatar a própria sociedade, conhecendo os modelos e os pressupostos utilizados para os construir, com o objetivo de desenvolver uma atitude crítica em relação a esses modelos".

De modo geral, a MF aborda temas da realidade. Além disso, contextualiza temas como porcentagem, funções afim, exponenciais e logaritmos, sequências, envolvendo inclusive a leitura e interpretação de quadros, tabelas e gráficos. Conforme Morgado (2002), a MF está ligada ao conteúdo de sequências, mais especificamente, progressões geométricas, cuja operação básica é a operação de empréstimos.

O autor ainda afirma que a finalidade em estudar MF consiste na 
tomada de decisões, para poder optar entre alternativas tanto de financiamento ou investimento. Considera que, para que se possa fazer alguma coisa útil em MF é preciso que entenda que o valor de uma quantia não depende apenas da quantidade, depende também da época a qual o valor está referido.

A proposta está estruturada em seis temas, a saber: introdução a MF, conceitos básicos, juros, taxas, aplicações e empréstimos. Cada conteúdo abordado foi pensado a partir de uma situação realmente vivida por um cidadão. $\mathrm{O}$ corpus das atividades baseia-se em notícias de jornais, revistas e internet e a escolha desses recursos justifica-se pela necessidade de informação e de alternativas em uma tomada de decisões. Um cidadão bem informado é cônscio a analisar e tomar decisões que lhe sejam convenientes.

Como gestor de sua sala de aula, o professor deve garantir uma aprendizagem que atue na formação de cidadãos capazes de agir na sua realidade, transformando-a. Ao planejar as ações em sala de aula, o professor precisa ter segurança para selecionar situações de aprendizagem. Estas podem ser propostas a partir de questões expressas em circunstâncias do dia a dia de seus alunos. É importante que cada professor conheça a realidade de seus alunos e a partir de seu conhecimento, introduza atividades que lhes retornem em conhecimento.

Neste artigo apresentaremos três assuntos da proposta que, geralmente não tem sido abordado no
Ensino Médio: taxas, aplicações e empréstimos.

Quanto ao estudo de taxas, sugere-se ao professor trabalhar o conceito de taxas equivalentes e taxas proporcionais, bem como possa ensinar a diferença entre taxa nominal e taxa efetiva. A escolha por esse tópico dá-se por necessitar informar ao estudante, enquanto cidadão, como tais taxas são abordadas. Esse é assunto que facilmente pode ser mascarado na sociedade, induzindo as pessoas a uma interpretação errada. A figura 1 apresenta a introdução à proposta.

4 TAXAS

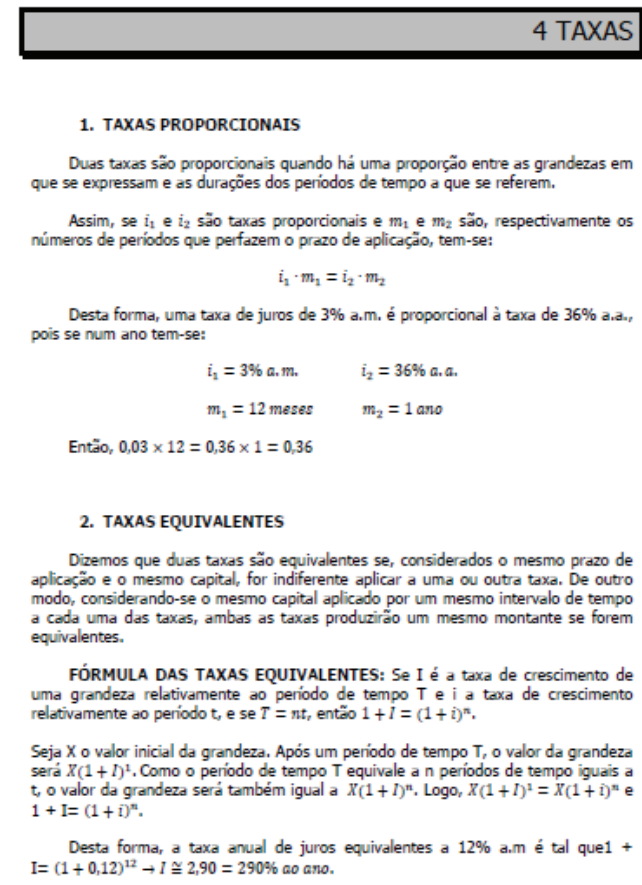

Figura 1 - sugestão da proposta para abordagem sobre taxas.

A atividade, que pode ser visualizada na figura 2 aborda as transformações de taxas com auxílio de planilhas eletrônicas. 




Figura 2 - abordagem com o uso de planilhas.

Foram pensados também em algumas atividades para serem trabalhadas em sala de aula, conforma ilustra a figura 3 .



Figura 3 - exemplos de atividades para serem trabalhados em sala de aula.

Depois de trabalhado o conceito de juros, sugere-se ao professor ousar em aplicar problemas que realmente façam sentido na vida dos estudantes.
$\mathrm{Na}$ realidade só existe um único problema de MF: deslocar quantias no tempo.

Observe que já trabalhamos o conceito de que certa quantia $A$, equivale no futuro, depois de $\mathrm{n}$ períodos de tempo, a $F=A(1+i)^{n}$. Decorre daí que para obter o valor futuro, basta multiplicar o valor atual por $(1+i)^{n}$, e para obter o valor atual, basta dividir o valor futuro por $(1+i)^{n}$.

Este é o princípio básico da equivalência de capitais. Sugere-se trabalhar esses conceitos, porque frequentemente o cidadão se depara com situações que analisam quantias no tempo. Quando tem que escolher entre pagamento à vista ou prazo, se é vantajoso comprar um utensílio novo ou alugá-lo, são exemplos de situações em que se podem tomar decisões a partir da matemática.

Desse modo é necessário que o professor comece discutir sobre essas aplicações da matemática, mesmo que já tenha feito em algum outro momento.

$\mathrm{Na}$ proposta de atividade, são apresentados exemplos de aplicações de MF onde, o principal objetivo é trabalhar a tomada de decisão, entre opções de pagamento à vista ou a prazo. A figura 4 ilustra uma situação de aplicação. 


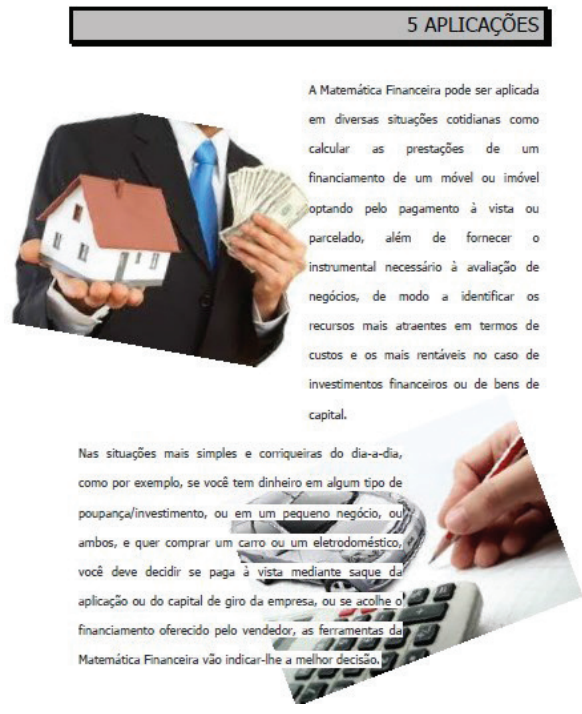

Figura 4 - apresentação do capítulo sobre aplicações.

Nos demais exercícios são tratados conceito de séries uniformes, ou seja, um conjunto de valores (ou pagamentos) iguais e igualmente espaçados no tempo.

Assim, o valor da série na época 0 (data inicial) é $A=\frac{P}{1+i}+\frac{P}{(1+i)^{2}}+\frac{P}{(1+i)^{3}}+$ $\cdots+\frac{P}{(1+i)^{n}}$, que representa a soma dos termos de uma PG de razão $\frac{1}{1+i^{\prime}}$, em que A é o valor da série e $\mathrm{P}$ o pagamento, conforme a figura 5.

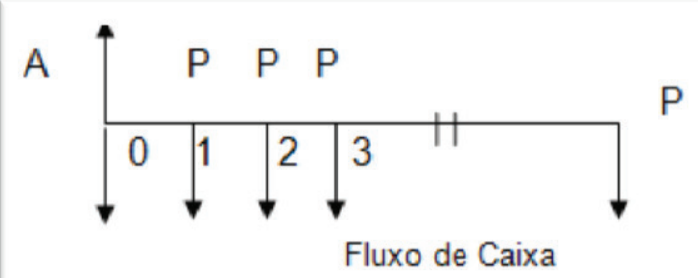

Figura 5 - apresentação do fluxo de caixa.

Os exercícios propostos representam algumas situações que podem servir de referência a outras, destacando mais uma vez a necessidade do aluno visualizar a situação apresentada em um fluxo de caixa, a figura 6 ilustra algumas das atividades propostas.

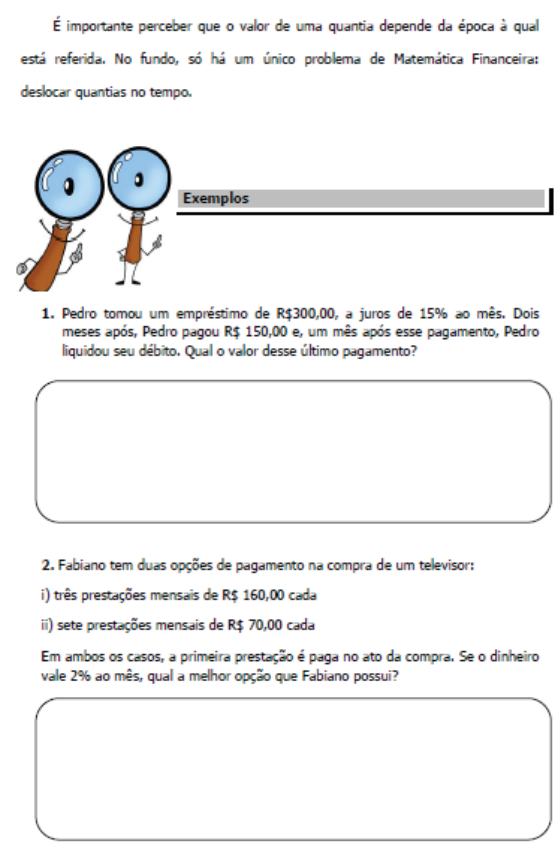

Figura 6 - exemplos para sala de aula.

Outra sugestão desta proposta didática é a abordagem do assunto de empréstimos, conforme apresenta a figura 7.

6 EMPRÉSTIMOS

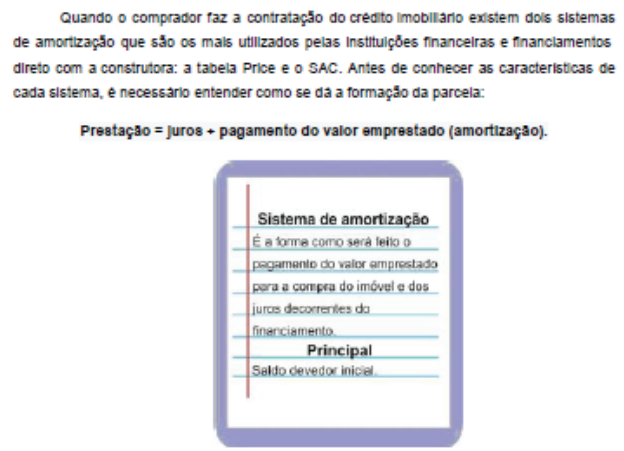

No caso da Tabela Price, também chamada de Sistema Francés de Amortização, o método de cálculo está em manter parcelas iguais. Como as prestạ̧̄es são constantes, ao longo do financiamento, a parte que cabe à amortização aumenta, enquanto o saldo devedor do juro diminui, ou seja, nas primeras parcelas o valor maior será correspondente ao juro e o restante será referente ao montante emprestado.



Já na tabela SAC, as prestaçōes iniciais sẫo mais altas, mas as amortizạ̣óes do saldo devedor săo constantes. Considerando que as parcelas fixas da prestaçăo diminuem o saldo da divida, os juros aplicados são, consequentemente, cada vez menores. Portanto, o valor das prestaçöes é decrescente.

Figura 7- apresentação do capítulo.

Esse conteúdo geralmente não é abordado no ensino médio, mas é importante que faça parte do currículo, 
pela necessidade de informação que o aluno deve obter ao concluir esta etapa de escolarização, ou ainda, que tenha condições de tomar decisões sensatas quando solicitadas. O que sugerimos é uma abordagem simples, de conceitualização, isto é, o que significa um sistema PRICE ou SAC e um comparativo e ambos, conforme a figura 8.

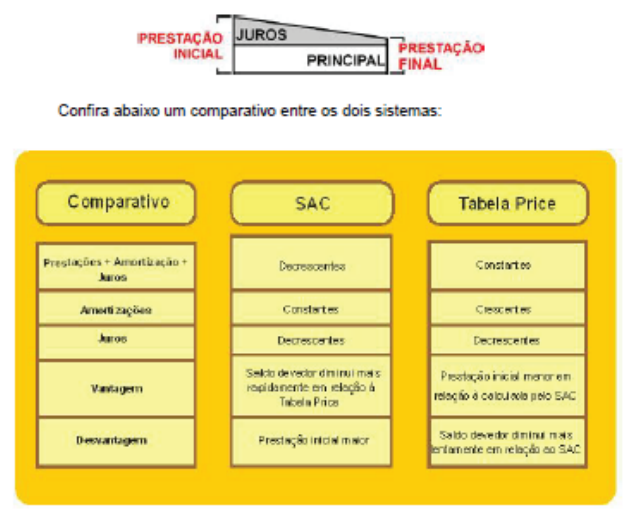

Segundo Manoel Maia (2012), vice-presidente do Secovi-Rio, do ponto de vista de custo, os planos säo equivalentes. A diferença entre quem opta pela Tabela Price ou SAC está na condição financeira da pessoa. Maia (2012) destaca que o SAC é ideal para pessoas que queiram reduzir o valor das prestaçóes ao longo do financiamento, pagando menos por més ao final do prazo. Já a Tabela Price, de acordo com ele é indicada para os profissionis com grandes chances promoções ou aumento de salário $e$, consequentemente, uma redução relativa ao custo da parcela em seu orçamento.

Figura 8 - informações sobre empréstimos.

$\mathrm{Na}$ proposta, também se apresentam a resolução de alguns exercícios que envolvam esses conceitos. Acredita-se que essa é uma excelente oportunidade de utilizar a planilha Excel, conforme apresenta a figura 9 .

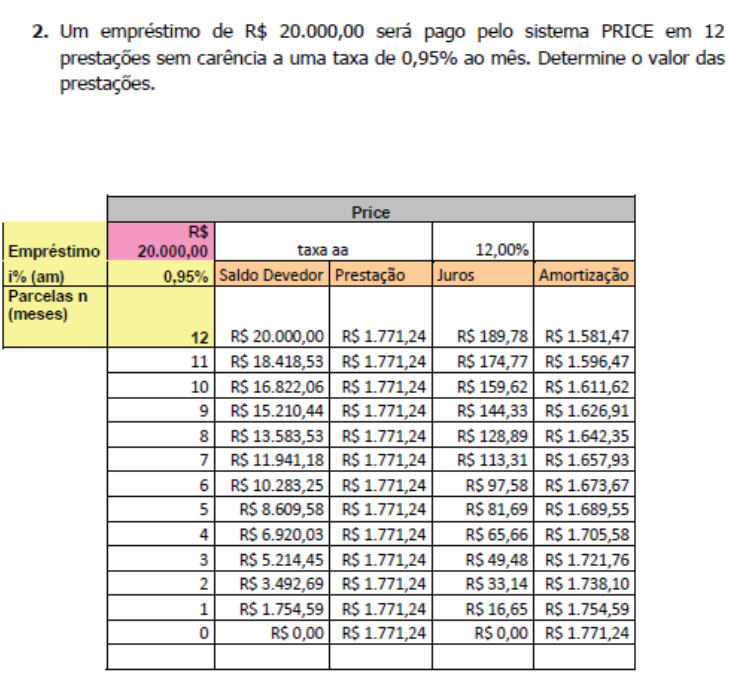

Figura 9- exemplo sobre PRICE.

\section{Conclusão}

O que se deseja propor por meio deste trabalho é uma educação pela Matemática. Precisamos ter certeza de que, ao final do Ensino Médio, o aluno seja capaz de reconhecer a Matemática nas relações sociais, mas que não seja formatado por ela, desenvolvendo consciência crítica para tomar decisões quanto a Matemática nas suas interações na sociedade.

Para isso, precisamos de professores comprometidos com educar matematicamente. Profissionais qualificados quanto ao uso de novas tecnologias, com uma formação sólida capaz de dar suporte as mais difíceis situações que possam ocorrer. Professores conscientes para reverem suas concepções e conceitos, já que a cada ano os alunos também compartilham de conhecimentos variados. Assim, para que o ensino da Matemática seja o mais eficiente possível, é necessário que a Matemática seja apresentada conforme as transformações necessárias à sociedade. 
Dessa forma, a proposta didática aqui apresentada, sugere a professores de Matemática uma abordagem de conteúdos de MF que sejam significativos aos alunos. Os temas e situações reais sugeridos podem fazer parte da vida de cada estudante, dando suporte a futuras decisões que possam ocorrer nas interações em que se envolverem.

Sabemos que o ensino de MF ainda está muito além do necessário em nossas escolas e que, como apontaram as leituras indicadas nesta pesquisa, à abordagem de conteúdos apresentada em livros didáticos tem sido muito precária e, muitas vezes, distante da realidade dos alunos. Sendo assim, sugerimos que cada professor, ao trabalhar em sala de aula, na perspectiva da EMC, observe, primeiramente, a realidade em que seus alunos estão inseridos, e procure a partir disso identificar quais conceitos de MF serão necessários para uma formação consciente e crítica de seus alunos.

A proposta de atividades pedagógicas para o ensino da $\mathrm{MF}$, por meio de conteúdos matemáticos contextualizados, parece favorecer o estabelecimento de relações mais significativas, uma vez que os alunos podem analisar situações em seu dia a dia, no cotidiano de seus pais, amigos ou conhecidos.

Com isso, percebemos que o desenvolvimento de uma prática pedagógica que leve os alunos a identificar, interpretar, avaliar e criticar a matemática, de forma que contribua na formação de cidadãos livres, responsáveis e críticos, ainda precisa ser melhor trabalhada, principalmente, aplicada em sala de aula, para que possamos avaliar tais resultados.

Por outro lado, queremos que tal proposta favoreça o ensino da MF para que os estudantes envolvidos nesse processo de aprendizagem entendam melhor seus papéis sociais como consumidores, pesquisadores e, ainda, como futuros cidadãos ou profissionais da atual sociedade.

Que a proposta aqui apresentada, encoraje professores a tomar como prática pedagógica a construção de materiais pedagógicos condizentes com a realidade de seus alunos, para que sejam educados matematicamente numa sociedade crítica e consciente.

\section{Referências}

ALVES, A. S.; FIALHO, C.; MATOS J.F. "Cidadania e educação Matemática crítica: Investigação sobre o contributo da educação matemática na formação de cidadãos participativos e críticos" Lisboa - Portugal. 2003. Disponível em: http://www.seiem.es/publicaciones/arch ivospublicaciones/actas/Actas12SEIEM/ Apo24AlvesMatos.pdf . Acesso: Mai. 2014.

BORBA, M. C. Prefácio In: SKOVSMOSE, O. Educação Matemática Crítica: A questão da Democracia. Campinas, SP: Papirus, 2001.

BRASIL. Ministério da Educação. Parâmetros Curriculares Nacionais. Brasília, 2000. 
BRASIL. Ministério da Educação.

Parâmetros Curriculares Nacionais.

Brasília, 2006.

PAIVA, A. M. S. ; SÁ, I. P. . Educação

Matemática Crítica e Práticas

Pedagógicas. Revista Iberoamericana de

Educación (Online), v. 2, p. n. ${ }^{\circ}$ 55/2,

2011

MORGADO, A. C., MATEMÁTICA

Financeira: A Matemática do Ensino

Médio, Direção de IMPA. Rio de

Janeiro, RJ: Instituto de Matemática

Pura e Aplicada, [2002]. (82 min),

SKOVSMOSE, O. Educação Matemática

Crítica - A questão da democracia.

Campinas, SP: PAPIRUS, 2001. 